\title{
Intracystic therapies for cystic craniopharyngioma in childhood
}

\author{
Ute Bartels $^{1}{ }^{*}$, Normand Laperriere $^{2}$, Eric Bouffet ${ }^{1}$ and James Drake ${ }^{3}$ \\ ${ }_{1}$ Paediatric Brain Tumour Program, Division of Haematology/Oncology, The Hospital for Sick Children, Toronto, ON, Canada \\ ${ }^{2}$ Department of Radiation Oncology, Princess Margaret Hospital, Toronto, ON, Canada \\ ${ }^{3}$ Division of Neurosurgery, The Hospital for Sick Children, Toronto, ON, Canada
}

\section{Edited by:}

Ursula B. Kaiser, Brigham and

Women's Hospital, USA

\section{Reviewed by:}

Edward Raymond Laws, Brigham and

Women's Hospital, USA

Laurence Katznelson, Stanford

University, USA

*Correspondence:

Ute Bartels, Division of

Haematology/Oncology, The Hospital

for Sick Children, 555 University

Avenue, Toronto, ON, Canada M5G

$1 \times 8$.

e-mail: ute.bartels@sickkids.ca
Introduction: Craniopharyngioma of childhood are commonly cystic in nature. An intracystic catheter insertion and subsequent instillation of substances inducing cyst shrinkage seems a beneficial strategy avoiding additional morbidity in a highly vulnerable brain location. Methods: A systematic review of the medical literature was performed to identify potentially relevant, all languages articles using Ovid MEDLINE and EMBASE from inception to July 2011 and Cochrane Central Register of Controlled Trials to third quarter 2011. All references were examined for relevancy. Results: Of 142 unique references, 71 referred to substances used for intracystic craniopharyngioma treatment. General aspects of intracystic catheter insertion as well as response rates, risks, and outcomes of children treated with intracystic radioisotopes, bleomycin, and interferon (IFN) are critically reviewed and an outline for potential future endeavors provided. Conclusion: IFN seems currently the intracystic substance with the best benefit risk ratio. The authors advocate for consensus on prospective data collection and standardized intracystic treatment strategies to allow reliable comparisons and herewith optimize treatment and outcome.

\section{INTRODUCTION}

Craniopharyngioma of childhood are commonly cystic in nature. These tumors are histologically benign, corresponding to WHO grade I and are usually not life threatening. Benign lesions in the brain are considered cured when amenable to surgical resection, however even gross total resection of craniopharyngioma is not always curative and may be associated with significant additional morbidities (Müller, 2010). Craniopharyngioma diagnosed in childhood will affect the developing child, the maturing brain and body via effects on the visual, endocrinological, metabolic, and neurocognitive functions in a more significant way as compared to adults. Therefore the Hippocrates' basic principle "to help or at least to do no harm" is the ultimate challenge when determining the best means for treating childhood craniopharyngioma and minimizing morbidity is a major goal.

Hence the prospect of a minimally invasive intervention such as an endoscopic insertion of a catheter with a subcutanous Ommaya reservoir - and subsequent instillation of substances inducing shrinkage of the craniopharyngioma cyst(s), seems a promising strategy. The following article reviews the experiences and outcomes of children treated with intracystic therapies providing a critical summary and an outline for potential future endeavors.

\section{METHODS}

A systematic review of the medical literature was performed to identify potentially relevant, all languages articles using Ovid MEDLINE and EMBASE from inception to July 2011 and Cochrane Central Register of Controlled Trials to third quarter
2011. The search strategy comprised a text search with medical subject headings $(\mathrm{MeSH})$ and free text terms used in combination including craniopharyngioma, intracystic treatment, cyst*, antineoplastic, and antibiotic. The total retrieval was 211 references from the 3 databases. All references were saved in an EndNote library used to identify the 69 duplicates for a total of 142 unique references. All references were examined for relevancy.

\section{RESULTS}

\section{NEUROSURGICAL ASPECTS OF INTRACYSTIC CATHETER INSERTION}

Fenestration as a "minimal" surgical intervention in the treatment of cystic craniopharyngioma was employed by Cushing in 1930. He and others recognized early on that the benefit from this intervention was of short duration with recurrence of symptoms within a short period of time (Kramer et al., 1961). This still holds true in a recent study which confirmed high recurrence rates when surgery was limited to cyst fenestration even with combined adjuvant Gamma knife surgery (Park et al., 2011).

An insertion of a catheter into a cystic craniopharyngioma may prevail over the transient success of a cyst fenestration by allowing repetitive drainage of the tumor cyst and the opportunity of instillation of intracystic substances. Different neurosurgical techniques are employed for the placement of catheters.

Surgical strategies for intracystic catheter placement are reported in a retrospective review of 50 cystic craniopharyngioma patients treated at two French (Paris, Marseille) and three Brazilian (Belo Horizonte, Goiânia, São Paulo) institutions between 1990 and 2000. The authors distinguish three different patient groups according to the different surgical approaches. Although 
with limited certainty from the data provided, the study included mainly pediatric patients. There is an age range $(9$ months to 21 years) given for the 25 female patients; a median age of 10 years is indicated for the male patients. Group one $(n=26)$ had their catheters placed either via frontal or pterional craniotomy under direct vision. Group two $(n=14)$ underwent stereotactic placement and group three $(n=11)$ had free hand placement through a burr hole. All catheters were connected to either a Rickham $(n=23)$ or an Ommaya reservoir subcutaneously. One to two weeks after the surgical intervention a permeability study (injection of contrast medium into the cyst via reservoir) using either $\mathrm{X}$-ray or CT was undertaken revealing contrast leakage or misplacement of the intracystic catheter in eight children (16.3\%). This study did not find a difference in complications between the three different surgical methods and reported that no other catheter placement related complication occurred in this series (Zanon et al., 2008).

Pettorini et al. (2009) advocate that neuroendoscopic positioning of the catheter is a safer option than open or stereotactic approaches. In their case series of eight patients (five children with a mean age 3.8 years) with symptomatic cystic craniopharyngioma the placement of the catheter via endoscopy with a Storz rigid ventriculoscope was without complications except one technical failure $(12.5 \%)$. The technical failure occurred in a child with an extensively calcified cyst wall that made positioning of the catheter impossible. For planning reasons a pre-op CT seems important as calcifications could be missed on MRI scans which are commonly the preferred imaging modality in children in order to minimize radiation exposure. Other advantages in using the endoscopic approach are the possibility to perform a septostomy at the same time, an intervention that establishes connection between lateral ventricles and subsequently facilitates successful shunting.

Stereotactic endoscopic technique as a safe and effective procedure for catheter insertion in cystic craniopharyngioma is supported by Joki et al. (2002). Hellwig et al. (1995) describe effective management in more than 70 cystic intracerebral space occupying lesions without major tissue traumatization. They reported an operative morbidity of less than $3 \%$ and no operative mortality.

There are anatomic constraints that may limit the stereotactic accessibility of a craniopharyngioma cyst which relate to infra- or suprasellar location and the vulnerability of the adjacent critical structures such as optic apparatus, pituitary gland, and hypothalamus (Floyd et al., 2009).

The experience of the operating neurosurgeon in a certain technique will ultimately affect the outcome. Interestingly in a study by Sanford (1994) the experience of the operating neurosurgeon was proven statistically significant with respect to the quality of life of craniopharyngioma patients.

\section{INSTILLATION OF SUBSTANCES}

The majority of cystic craniopharyngioma arise from squamous epithelium (Ingraham and Scott, 1946; Kramer et al., 1961; Louis et al., 2007). Intracystic instilled substances should have the ability to destroy the secretive properties of the epithelial cell lining to induce cyst shrinkage and ideally subsequent adhesion of the cyst wall. Substances should remain within the cyst and should not cause any harm to the surrounding brain in case of leakage. Substances used for cystic craniopharyngiomas have been radioisotopes, Bleomycin, and Interferon (IFN) (Table 1).

Intracystic instillation of $\beta$ emitting radioisotopes including aurum $^{198}$, rhenium ${ }^{186}$, yttrium ${ }^{90}$, and phosphorus ${ }^{32}$ has been reported successful in inducing craniopharyngioma cyst shrinkage in multiple studies over more than four decades (Backlund, 1973, 1989; Musolino et al., 1985; Voges et al., 1997; Hasegawa et al., 2004).

While phosphorus ${ }^{32}$ is the only $\beta$ emitting radionucleotide available for use in the USA, rhenium ${ }^{186}$, yttrium ${ }^{90}$, and phosphorus $^{32}$ are available and used in Europe (France/Hungary/ Germany) (Voges et al., 1997; Julow et al., 2007; Derrey et al., 2008). Physical characteristics of $\beta$ emitting radioisotopes may determine preferences. Some authors favor phosphorus ${ }^{32}$ with a lower energy (mean $\beta$ energy of $0.69 \mathrm{MeV}$ ), longer half life ( 14.3 days), and less tissue penetration (2-8 mm; Pollock et al., 1995) while others argue that yttrium ${ }^{90}$ (mean $\beta$ energy of $0.93 \mathrm{MeV}, 2.7$ days half life, tissue penetration $11 \mathrm{~mm}$ ) is superior due to its higher emitting dose during a shorter time period (Blackburn et al., 1999). Clinical studies, mostly institutional retrospective series, are equivocal regarding the clinical superiority of a radioisotope. Voges et al. (1997) observed no cyst response to intracystic rhenium ${ }^{186}$, while intracavitary irradiation using yttrium ${ }^{90}$ or phosphorous ${ }^{32}$ was highly effective resulting in $79.5 \%$ response rates. In a more recent study including 11 children within 42 eligible patients, the instillation of colloidal rhenium ${ }^{186}$ resulted in $74 \%$ response rate including 17 patients with complete cyst retraction and 12 patients with $>50 \%$ reduction in cyst volume (Derrey et al., 2008). Barriger et al. (2011) report an overall cyst control rate of $67 \%$ with intracystic phosphorus ${ }^{32}$ in 19 patients between 3 and 54 years of age.

Radioisotope doses require adjustment to cyst volume. The optimal prescribed dose to the cyst wall is 200-300 Gy (Hechtman et al., 2005; Sadeghi et al., 2007) up to 400 Gy with significant increased risks especially to the optic apparatus once doses surpass 400 Gy (Derrey et al., 2008; Floyd et al., 2009). There is evidence that cyst volumes exceeding $100 \mathrm{ml}$ will not respond well (Albright et al., 2005).

Instillation of phosphorus ${ }^{32}$ into a recurrent infrachiasmatic cystic craniopharyngioma of a 36-old-female via an neuroendoscopic transnasal route was described recently (Floyd et al., 2009) and is certainly an elegant minimal invasive intervention. A therapeutic effect was achieved with one instillation only and therefore the insertion of a permanent catheter with reservoir was not required. However a catheter implantation is usually employed for radioisotopes injection and removal (Derrey et al., 2008).

Access to radioisotopes is only available in a limited number of institutions requiring sophisticated equipment and a multidisciplinary team of experts and there is advocacy using this treatment approach only for tumors that recur after both surgery and external beam radiation therapy (Becker et al., 1999; Merchant et al., 2006).

In 1974 the effect of bleomycin for cultured craniopharyngioma cells and intracystic concentration of bleomycin was published by Kubo et al. (1974). Based on their morphological observations of destruction of cell arrangement, cytolysis, and karyopyknosis they concluded its local cytotoxic potency to craniopharyngiomas. 
Table 1 | Intracystic treatment modalities in craniopharyngiomas - retrospective reviews including children.

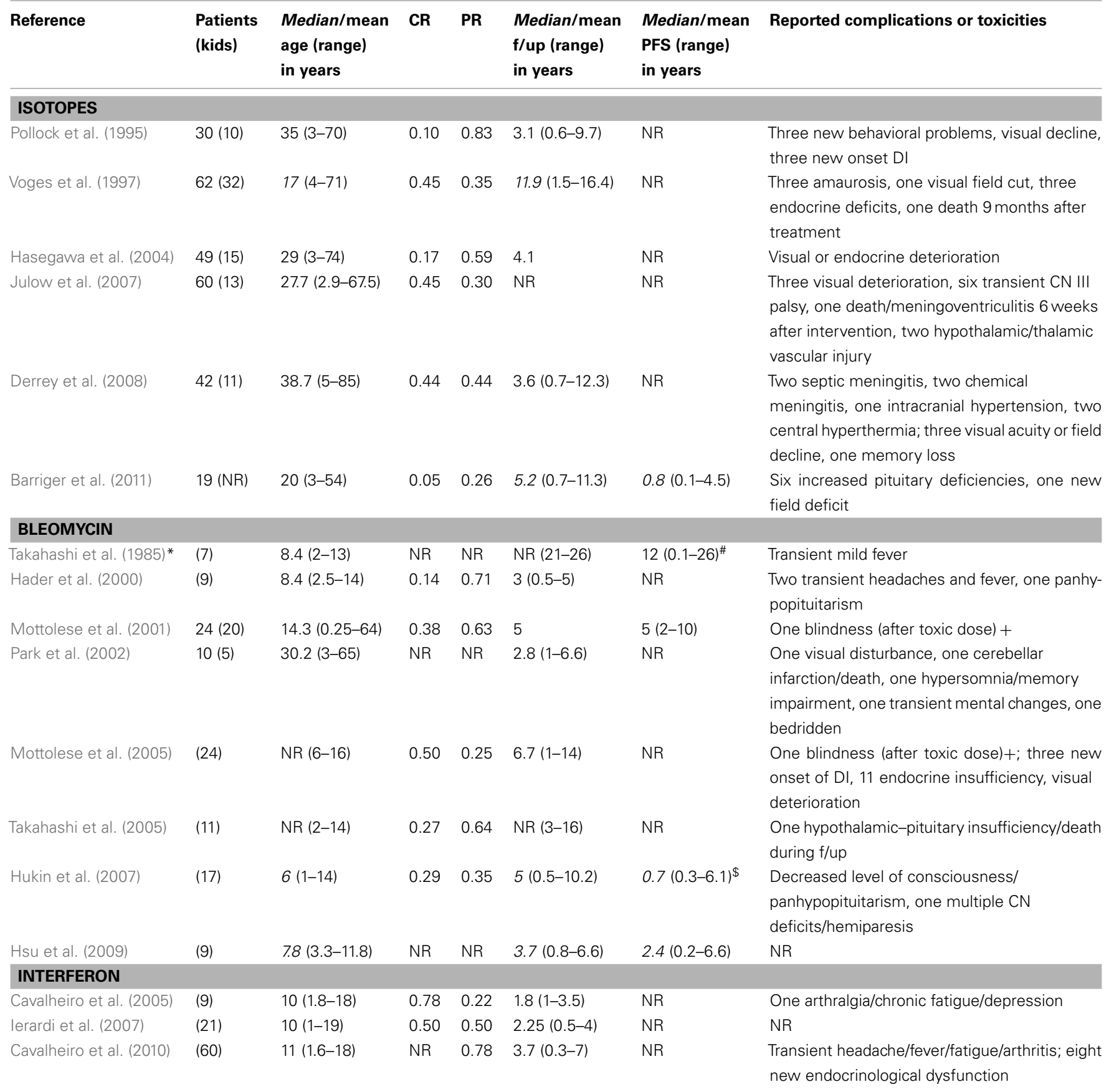

*Including f/up data provided in Takahashi et al. (2005).

*Estimate from authors based on provided data.

+ Likely same patient.

${ }^{\$}$ Refers to 12 patients treated at the time of the initial diagnosis.

$N R$, not reported; PFS, progression free survival; CR, complete response; PR, partial response ( $\geq 50 \%$ shrinkage); f/up, follow-up; CN, cranial nerve.

They were the first to report on intracystic bleomycin treatment in an 8-year-old boy with craniopharyngioma who had failed radiation. A mixture of bleomycin, dextran sulfate, and dexamethasone was injected into his cyst via ommaya reservoir. Treatment was given twice during the first week. No significant side effects were observed and subsequently intracystic injections were given 5 days during the second week, followed by instillations every second day on an outpatient basis. A total dose of $30 \mathrm{mg}$ bleomycin 
was administered resulting in partial cyst reduction as evaluated with pneumocystography. The boy was reported well at 1 month follow-up.

Takahashi et al. (1985) published a case series on seven children with craniopharyngioma treated with intracystic instillation of Bleomycin.By labeling Bleomycin with cobalt-57 and subsequent measurements with a gamma-ray camera a $3 \mathrm{~h}$ half life of intracystic Bleomycin with a drop to $10 \%$ of the initial activity $24 \mathrm{~h}$ later was calculated. This surveillance determined the subsequent treatment regimen administering intracystic instillation of $1-5 \mathrm{mg}$ bleomycin every other day. The authors further observed that with ongoing intracystic instillation of bleomycin the initial motor-oil like fluid content changed to nearly colorless fluid and initial high lactate dehydrogenase ( $\mathrm{LDH}$ ) levels dropped. Hence treatment was given until cystic fluid became almost colorless and LDH levels decreased below 1000 units. The seven children received a mean dose of $46 \mathrm{mg}$ of intracystic bleomycin ranging from 13 to $95 \mathrm{mg}$. Four children had sustained response without evidence of progression at 2, 4, and 7 years follow-up. Three children died, two of them due to recurrent disease 1.5 and 2 years later respectively. One child died 1.5 months later without evidence of progression; further details are lacking. Autopsies in two of the children did not reveal any bleomycin associated changes in the adjacent brain structures.

Since Takahashi's publication in 1985 several pediatric case reports (Cavalheiro et al., 1996; Savas et al., 1999; Alen et al., 2002) and retrospective institutional case series confirmed intracystic bleomycin's effectiveness in inducing craniopharyngioma cyst shrinkage with sustained response rates in children (Takahashi et al., 1985, 2005; Hader et al., 2000; Franzini et al., 2001; Mottolese et al., 2001, 2005; Hernandez et al., 2002; Park et al., 2002; Hukin et al., 2005, 2007; Kim et al., 2007; Hsu et al., 2009; Yang et al., 2009). All studies refer to small sample sizes including a maximum of 22 pediatric patients (Franzini et al., 2001) with five studies reporting response to treatment in all patients (Mottolese et al., 2001; Park et al., 2002; Hukin et al., 2005; Takahashi et al., 2005; Kim et al., 2007). Complete response rates in children vary from $29 \%$ as provided by the Canadian experience (Hukin et al., 2007) to 67\% (Mottolese et al., 2005) in the Lyon experience, where 12 of 18 children showed disappearance of the cyst with maintained responses at a mean follow-up of 6 years 8 months.

The schedules of bleomycin administration and doses vary and range from daily to weekly administrations with single doses ranging from 1 to $15 \mathrm{mg}$ and total doses ranging from 14.5 to $180 \mathrm{mg}$ per course (Takahashi et al., 1985; Jiang et al., 2002; Park et al., 2002). No standardized regimen has been established. Of note is that the former bleomycin mg dose was labeled a misnomer and should be substituted by Unit ( $1 \mathrm{mg}$ equals $1 \mathrm{U}$ ). Stefanou underscored the considerable problems and dangers due to different bleomycin nomenclature in the US, Europe, and Australia and advocated for standardization as a mean to minimize dosing errors (Stefanou and Siderov, 2001).

Several studies investigated intracystic fluid LDH to prognosticate tumor response. While some studies observed decreased $\mathrm{LDH}$ levels consistent with response and increased $\mathrm{LDH}$ levels with recurrence (Takahashi et al., 1985; Park et al., 2002) others did not confirm LDH levels reflective of tumor response (Cavalheiro et al., 1996; Mottolese et al., 2001; Jiang et al., 2002; Caceres, 2005).

Intracystic bleomycin is usually well tolerated and most common acute side effects include mild headaches (with or without nausea/vomiting) and transient fever. However serious concerns relate to the risk of leakage of the neurotoxic bleomycin into the cyst surrounding parenchyma with associated morbidities and even mortality. Despite verification of appropriate positioning of the catheter intracystic bleomycin is associated with a risk of significant toxicities including transient and persistent hypothalamic injury (Haisa et al., 1994; Park et al., 2002; Lafay-Cousin et al., 2007), seizures and hemiparesis (Jiang et al., 2002; Park et al., 2002; Belen et al., 2007; Hukin et al., 2007), panhypopituitarimus (Hader et al., 2000; Hukin et al., 2007), blindness (Mottolese et al., 2001; Belen et al., 2007), and death (Savas et al., 2000). A prospective randomized study evaluating intracystic bleomycin $(n=5)$, intracystic radiotherapy with phosphorus ${ }^{32}(n=5)$, and a combination of both substances $(n=9)$ revealed severe complications for the combined therapy resulting in thalamic infarction and death in two patients (Jiang et al., 2002).

Jakacki et al. (2000) used subcutanous IFN for the treatment of cystic craniopharyngioma based on the fact that craniopharyngioma and squamous cell skin carcinoma originate from the same cells and evidence of clinical activity of IFN in squamous cell skin carcinoma in early trials. In their study 15 craniopharyngioma patients (4.2-19.8 years old) underwent daily subcutanous IFN- $\alpha 2 \mathrm{a}\left(8,000,000 \mathrm{U} / \mathrm{m}^{2}\right)$ injections. Three patients could not be evaluated for response. Of the remaining 12 patients, 3 patients had a radiologically confirmed response to IFN. All patients experienced fever during the first few days of treatment, usually accompanied by chills and myalgias. Seven patients required temporary discontinuation of the drug and/or dose reductions.

Intracystic instillation of interferon was first used by Cavalheiro and colleagues who published the first and largest experiences on children with cystic craniopharyngiomas (Cavalheiro et al., 2005, 2010; Ierardi et al., 2007). Their most recent publication (Cavalheiro et al., 2010) included 60 children with a mean age of 11 years ( 20 months-18 years) who were treated at three different institutions (Sao Paulo/Brazil, Santiago/Chile, Rome/Italy) from 2000 to 2009. Twenty-nine of the 60 patients received intracystic IFN after initial surgery $(n=18)$ or bleomycin treatment $(n=3)$ had failed and 31 were treated with IFN as a first line treatment. In 37 patients cyst volume was measured before and after therapy. The mean cyst volume of $27.7 \mathrm{ml}(3.3-134.5)$ before treatment decreased to a mean volume of $9.6 \mathrm{ml}(0.14$ $70.7)$ after therapy. While in 47 children (78\%) more than $50 \%$ cyst shrinkage was achieved at completion of therapy, 13 children progressed and required surgical intervention. Only onethird of the patients experienced some side effects consisting of either headaches $(n=6)$, palpebral edema (5), fever (5), chronic fatigue (1), or arthritis (1) not necessitating discontinuation of treatment. One patient required optic decompression due to lack of visual improvement despite cyst shrinkage and eight patients developed new endocrinological dysfunctions. There was no mortality. 


\section{ADMINISTRATION SCHEDULE:}

\begin{tabular}{|l|c|c|c|c|}
\hline \multicolumn{1}{|c|}{ Drug } & \multicolumn{1}{|c|}{ Route } & Dose & Weeks & Days \\
\hline $\begin{array}{l}\text { Interferon-alfa-2b } \\
\text { (Intron A - ready to } \\
\text { use solution) }\end{array}$ & Intracystic injection & $3,000,000 \mathrm{IU}$ & Weeks $1-4$ & $\begin{array}{l}\text { Wednesday } \\
\text { Friday }\end{array}$ \\
\hline $\begin{array}{l}1 \text { cycle }=4 \text { weeks treatment ( total dose per cycle }=36,000,000 \mathrm{IU}) \\
\text { Cycle may be repeated depending on response }\end{array}$ & \\
\hline Suggested dosage modifications: None
\end{tabular}

\section{Treatment Plan:}

Before initiation of treatment a permeability study should have ruled out leakage of contrast and confirmed appropriate position of the tip of the Ommaya catheter within the cyst. Permeability study recommended 2 weeks after catheter placement or later.

One Treatment Course encompasses 3 weekly (Mo, Wed, Fri) cystic aspirations followed by injection of 3,000,000 IU INTRON A ("ready-to-use") via Ommaya reservoir over 4 weeks time period (=12 injections resulting in a total dose of $36,000,000$ IU INTRON A).

At start of treatment course (day 1) the maximum possible amount of cystic fluid should be removed before injection of INTRON A, taking the result of the permeability study (cyst volume) into account. For all following aspirations/injections the following procedure description applies:

\section{Procedure description:}

Cystic fluid aspiration prior to INTRON A injection (at least $1.5-2 \mathrm{ml}$ if possible)

Injection of a total volume of $1 \mathrm{~mL}$ consisting of 3,000,000 IU Intron A "ready to use solution" diluted in preservative free normal saline (NS) provided in a vial from pharmacy followed by $0.7-1 \mathrm{~mL}$ NS flush.

FIGURE 1 | SickKids standard of care protocol for intracystic interferon administration

Based on Cavalheiros experience and initial publication a standard of care protocol was developed for intracystic IFN administration (Figure 1) in Toronto. The former intracystic treatment with bleomycin injection was discontinued due to our experience of bleomycin associated neurotoxicity (Lafay-Cousin et al., 2007). Roferon- ${ }^{\circledR}$ (IFN- $\left.\alpha 2 \mathrm{a}\right)$, the product used by Cavalheiro et al. $(2005,2010)$ is not available in Canada. Intron- $A^{\circledR}$ (IFN- $\alpha 2 b$ ) is available in Canada and although not specifically studied in the treatment of craniopharyngiomas, the ready to use formulation has been given intraventriculary via Ommaya reservoir for subacute sclerosing panencephalitis (SSPE; Gascon, 2003). In this randomized clinical trial including $121 \mathrm{SSPE}$ patients with a median age $8.5(3-22)$ years, IFN- $\alpha 2 \mathrm{~b}$ was initiated with a 5-day escalating regime from $100,000 \mathrm{U} / \mathrm{m}^{2}$ on day 1 to $1,000,000 \mathrm{U} / \mathrm{m}^{2}$ on day 5 followed by treatment of $1,000,000 \mathrm{U} / \mathrm{m}^{2}$ twice a week for 6 months. Fifty-nine patients were randomized to the IFN group. The main adverse effect reported was hyperpyrexia $(n=7)$ an expected side effect and well 
managed with regular antipyretics. From a clinical perspective, IFN- $\alpha 2 \mathrm{a}$ and IFN- $\alpha 2 \mathrm{~b}$ are considered interchangeable for their licensed indications, at equivalent doses. An "ideal" formulation of IFN has not been developed for administration via an Ommaya reservoir.

Since adoption of intracystic IFN at our institution six children between 4 and 18 years of age (mean 10.8 years) were treated. Response was measurable in five children with one complete response ( $>90 \%$ cyst shrinkage; Figure 2 ), three partial response ( $>50 \%$ shrinkage), and one stable disease. Sustained response was achieved after two to four treatment cycles with a median follow-up of 17 (1-30) months. All patients suffered manageable episodes of headaches, one associated with nausea and vomiting in the initial treatment period. None of the children suffered new endocrinological dysfunction, evidence of hypothalamic damage and none of them is obese.

Interferon belongs to a family of proteins with antiproliferative and immunomodulatory functions and its efficacy has been explained via FasL mediated activation of the apoptotic pathway (Ierardi et al., 2007). As such Pettorini et al. (2010) investigated protein content of the cystic fluid in six pediatric craniopharyngioma patients (mean age 4.5 years) and reported change in fluid content. Those three children who were treated with intracystic IFN resulting in near complete response after a one 4-week lasting course had significant decrease in their total alphadefensins (1-3) determined as relevant components of cyst fluids while the untreated control $(n=3)$ showed increased nanomoles of alpha-defensins.

\section{CONCLUSION}

Intracystic treatment options for cystic craniopharyngioma provide data suggestive of durable cyst shrinkage and benefit beyond a pure volume reduction due to repeated fluid aspirations. The effect however is limited to the cystic craniopharyngioma portion without an effect on the solid component. There are multiple challenges relating to technical practicalities: Multicystic occurrence may limit treatment to one cyst only and therefore this approach does not provide the clinical benefit as wished. The thickness of the cyst wall may not allow successful penetration of the scope/catheter into the cyst and different catheter designs make the correct intracystic positioning of the catheter and its holes difficult. Intraoperative ultrasound and computer tomography (CT) have aided to confirm correct catheter position; however volume changes during subsequent treatment may influence the intracystic catheter tip location.

Most institutions will perform a permeability study prior to the start of intracystic treatment. The timing of the permeability study/dye test depends on the specific institution and ranges from 5 days postoperatively to several weeks later (Caceres, 2005; Cavalheiro et al., 2010). A permeability study refers to a CT done after contrast is injected into the craniopharyngioma cyst to confirm that contrast will remain within the cyst and not leak outside (Figure 3). Leakage documented on an early performed permeability study has often resolved without further intervention on a follow-up test after some weeks (Hader et al., 2000). Outflow of substances may occur during treatment either as a result of cyst shrinkage exposing catheter holes outside of the cyst or as a result
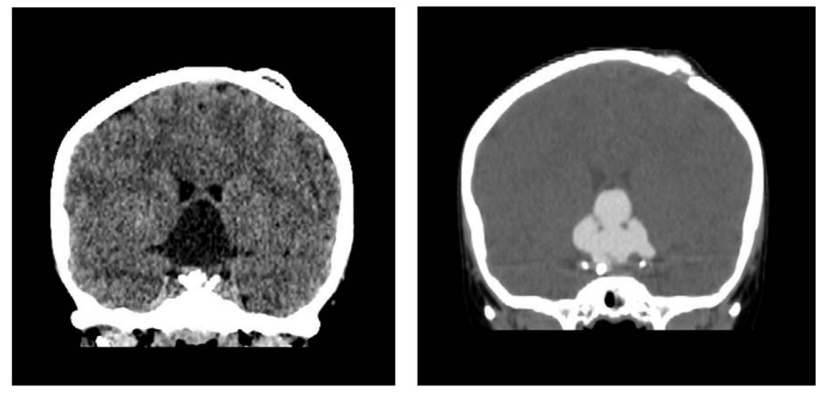

Before and after intracystic contrast administration: No leakage

FIGURE 3 | Permeability study.

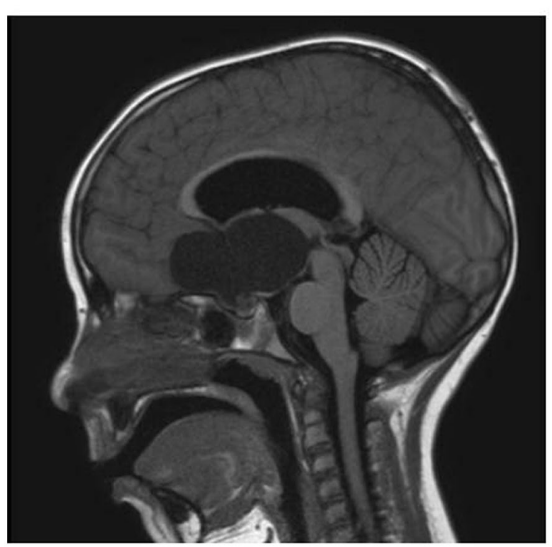

At diagnosis

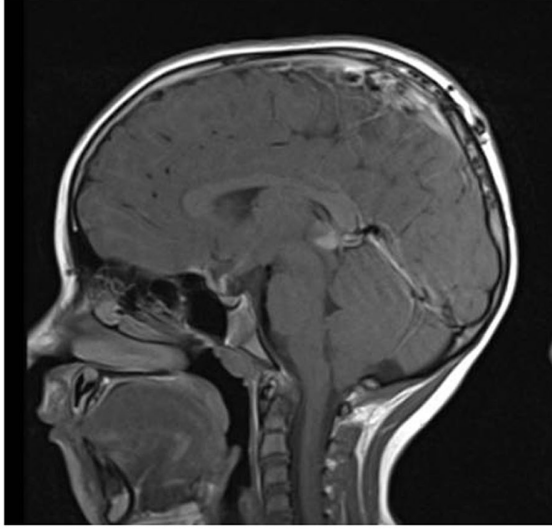

19 months later

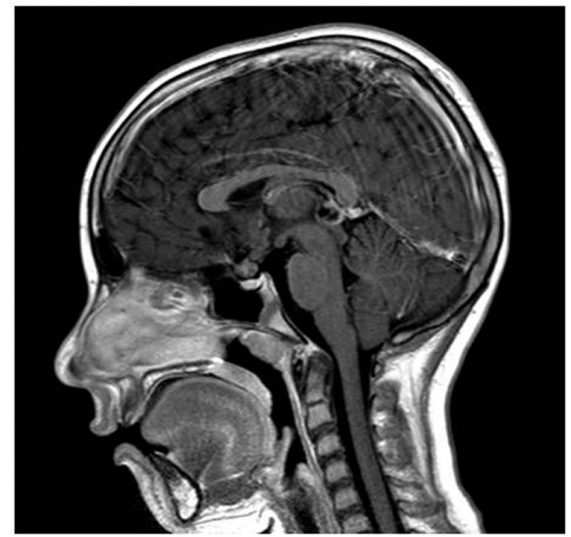

30 months later

FIGURE 2 | Child with complete maintained response after 2 courses with intracystic interferon. 
of increased permeability of the cyst wall (Lafay-Cousin et al., 2007).

Hence, despite all diligence, leakage of an intracystic substance remains a potential risk. Therefore a non-neurotoxic intracystic medication such as IFN presents a safer treatment option than radioisotopes or bleomycin and achieved impressive $78 \%$ complete and partial response rates after a one to nine treatment cycles (average 5; Cavalheiro et al., 2010).

Is cyst shrinkage the appropriate response measurement? A reduced cyst size will reduce increased pressure to the neighborhood structures and should translate into clinical benefit regarding visual, neurocognitive, endocrine, and metabolic function. However Cavalheiro et al. (2010) describe visual or endocrinological worsening in one and eight children respectively despite response to intracystic treatment.

Literature reviews concerning intracystic craniopharyngioma treatment strategies published over the recent years (Caceres, 2005; Hargrave, 2006; Linnert and Gehl, 2009; Steinbok and Hukin, 2010) capture the challenge of combining retrospective data from different institutions that refer to different doses, schedules, response definitions, and meaning of success. Cystic response and final outcome may not necessarily correlate. Prognostic marker need yet to be identified (Ierardi et al., 2007, 2009; Pettorini et al., 2010). Furthermore the role and value of intracystic treatment in

\section{REFERENCES}

Albright, A. L., Hadjipanayis, C. G., Lunsford, L. D., Kondziolka, D., Pollack, I. F., and Adelson, P. D. (2005). Individualized treatment of pediatric craniopharyngiomas. Childs Nerv. Syst. 21, 649-654.

Alen, J. F., Boto, G. R., Lagares, A., de la Lama, A., Gomez, P. A., and Lobato, R. D. (2002). Intratumoural bleomycin as a treatment for recurrent cystic craniopharyngioma. Case report and review of the literature. Neurocirugia (Astur) 13, 479-485; discussion 485.

Backlund, E. O. (1973). Studies on craniopharyngiomas. 3. Stereotaxic treatment with intracystic yttrium90. Acta Chir. Scand. 139, 237-247.

Backlund, E. O. (1989). Colloidal radioisotopes as part of a multi-modality treatment of craniopharyngiomas. J. Neurosurg. Sci. 33, 95-97.

Barriger, R. B., Chang, A., Lo, S. S., Timmerman, R. D., DesRosiers, C., Boaz, J. C., and Fakiris, A. J. (2011). Phosphorus-32 therapy for cystic craniopharyngiomas. Radiother. Oncol. 98, 207-212.

Becker, G., Kortmann, R. D., Skalej, M., and Bamberg, M. (1999). The role of radiotherapy in the treatment of craniopharyngioma-indications, results, side effects. Front. Radiat. Ther. Oncol. 33, 100-113.

Belen, D., Er, U., Yigitkanli, K., and Bolay, H. (2007). Delayed neurotoxic complication of intracavitary bleomycin therapy for craniopharyngioma in a child who had previously undergone radiosurgery. Case report. J. Neurosurg. 106, 391-393.

Blackburn, T. P., Doughty, D., and Plowman, P. N. (1999). Stereotactic intracavitary therapy of recurrent cystic craniopharyngioma by instillation of 90yttrium. Br. J. Neurosurg. 13, 359-365.

Caceres, A. (2005). Intracavitary therapeutic options in the management of cystic craniopharyngioma. Childs Nerv. Syst. 21, 705-718.

Cavalheiro, S., Dastoli, P. A., Silva, N. S., Toledo, S., Lederman, H., and da Silva, M. C. (2005). Use of interferon alpha in intratumoral chemotherapy for cystic craniopharyngioma. Childs Nerv. Syst. 21, 719-724.

Cavalheiro, S., Di Rocco, C., Valenzuela, S., Dastoli, P. A., Tamburrini, G., Massimi, L., Nicacio, J. M., Faquini, I. V., Ierardi, D. F., Silva, N. S., Pettorini, B. L., and Toledo, S. R. (2010). Craniopharyngiomas: intratumoral chemotherapy with interferon-alpha: a multicenter preliminary study with 60 cases. Neurosurg. Focus 28, E12.

Cavalheiro, S., Sparapani, F. V., Franco, J. O., da Silva, M. C., and Braga, F. M. (1996). Use of bleomycin in intratumoral chemotherapy for cystic craniopharyngioma. Case report. J. Neurosurg. 84, 124-126.

Derrey, S., Blond, S., Reyns, N., Touzet, G., Carpentier, P., Gauthier, H., and

postponing more aggressive surgery or radiation therapy will need to be defined.

Comparisons and reliable conclusions will remain difficult unless we as a medical community are agreeable on systematic evaluations and definitions. While randomized clinical trials are the gold standard for evaluation of best treatment strategies, they are certainly difficult in the context of rare tumors. Even so thoughts should be given to potential national and international cooperation for standardized intracystic treatment strategies. It's been 7 years that a European consensus was achieved regarding prospective data collection and definition of parameter for craniopharyngioma at a meeting of the International Society for Pediatric Oncology (SIOP; Müller et al., 2006). It is time to expand consensus on prospective data collection on craniopharyngioma patients to an international level. In doing so we will increase the size of comparable study cohorts, be able to evaluate meaningful differences and contribute to improved tailored patient care and wellbeing.

\section{ACKNOWLEDGMENTS}

Sincere thanks to Dr. Takaaaki Yanagisawa for providing translation of the original Japanese publications on bleomycin, to Ms. Anne $\mathrm{H}$. Longo for her excellent pharmacological assistance and to Mrs. Elizabeth M. Uleryk for her extensive literature research.

Dhellemmes, P. (2008). Management of cystic craniopharyngiomas with stereotactic endocavitary irradiation using colloidal 186Re: a retrospective study of 48 consecutive patients. Neurosurgery 63, 1045-1052; discussion 1052-1043.

Floyd, J. R., Cmelak, A., Russell, P., and Weaver, K. D. (2009). Endoscopic, image-guided, transnasal instillation of (32)P for recurrent infrachiasmatic cystic craniopharyngioma. Minim. Invasive Neurosurg. 52, 137-140.

Franzini, A., Leocata, F., Pintucci, M., and Broggi, G. (2001). Cystic craniopharyngioma: Stereotactic intracavitary Bleomycin administration. [Italian] La somministrazione di Bleomicina intracavitaria nel trattamento chirurgico del craniofaringioma cistico. Rivista Medica 7, 41-45.

Gascon, G. G. (2003). Randomized treatment study of inosiplex versus combined inosiplex and intraventricular interferon-alpha in subacute sclerosing panencephalitis (SSPE): international multicenter study. J. Child Neurol. 18, 819-827.

Hader, W. J., Steinbok, P., Hukin, J., and Fryer, C. (2000). Intratumoral therapy with bleomycin for cystic craniopharyngiomas in children. Pediatr. Neurosurg. 33, 211-218.

Haisa, T., Ueki, K., and Yoshida, S. (1994). Toxic effects of bleomycin on the hypothalamus following its administration into a cystic craniopharyngioma. Br. J. Neurosurg. 8, 747-750.

Hargrave, D. R. (2006). Does chemotherapy have a role in the management of craniopharyngioma? J. Pediatr. Endocrinol. 19(Suppl. 1), 407-412.

Hasegawa, T., Kondziolka, D., Hadjipanayis, C. G., and Lunsford, L. D. (2004). Management of cystic craniopharyngiomas with phosphorus32 intracavitary irradiation. $\mathrm{Neu}$ rosurgery 54, 813-820; discussion 820-812.

Hechtman, C. D., Li, Z., Mansur, D. B., Perez, C. A., Myerson, R. J., Simpson, J. R., Anders, J. C., Wu, C., and Palucci, C. A. (2005). Dose distribution outside of a sphere of P-32 chromic phosphorous colloid. Int. J. Radiat. Oncol. Biol. Phys. 63, 961-968.

Hellwig, D., Bauer, B. L., and ListHellwig, E. (1995). Stereotactic endoscopic interventions in cystic brain lesions. Acta Neurochir. Suppl. 64, 59-63.

Hernandez, J., Morel, C., Gonzalez, A., Garcia, S., Hernandez, M., and Zarate, A. (2002). Use of bleomycin through a local reservoir in patients with cystic craniopharyngiomas. [Spanish] Uso de la bleomicina mediante un reservorio local en pacientes con craneofaringiomas quisticos. Medicina Interna de Mexico 18, 273-277. 
Hsu, T. R., Chang, K. P., and Wong, T. T. (2009). Intracystic bleomycin therapy for craniopharyngioma in children. Neuro-oncology 11, 902.

Hukin, J., Steinbok, P., Lafay-Cousin, L., Hendson, G., Strother, D., Mercier, C., Samson, Y., Howes, W., and Bouffet, E. (2007). Intracystic bleomycin therapy for craniopharyngioma in children: the Canadian experience. Cancer 109, 2124-2131.

Hukin, J., Visser, J., Sargent, M., Goddard, K., Fryer, C., and Steinbok, P. (2005). Childhood craniopharyngioma: Vancouver experience. Childs Nerv. Syst. 21, 758-765.

Ierardi, D., Pinhal, M. A., Coelho, B. V., Martins, J. R., Thomazini-Gouveia, J., Silva, N. S., De Toledo, S. R. C., and Cavalheiro, S. (2009). Expression analysis of hialuronic acid sintases and hyaluronidases in craniopharyngiomas tissue and quantification of hyaluronic acid in intratumoral liquid during alpha interferon chemotherapy. Pediatr. Blood Cancer 53, 826-827.

Ierardi, D. F., Fernandes, M. J., Silva, I. R., Thomazini-Gouveia, J., Silva, N. S., Dastoli, P., Toledo, S. R., and Cavalheiro, S. (2007). Apoptosis in alpha interferon (IFN-alpha) intratumoral chemotherapy for cystic craniopharyngiomas. Childs Nerv. Syst. 23, 1041-1046.

Ingraham, F. D., and Scott, H. W. Jr. (1946). Craniopharyngiomas in children. J. Pediatr. 29, 95-116.

Jakacki, R. I., Cohen, B. H., Jamison, C., Mathews, V. P., Arenson, E., Longee, D. C., Hilden, J., Cornelius, A., Needle, M., Heilman, D., Boaz, J. C., and Luerssen, T. G. (2000). Phase II evaluation of interferon-alpha-2a for progressive or recurrent craniopharyngiomas. J. Neurosurg. 92, 255-260.

Jiang, R., Liu, Z., and Zhu, C. (2002). Preliminary exploration of the clinical effect of bleomycin on craniopharyngiomas. Stereotact. Funct. Neurosurg. 78, 84-94.

Joki, T., Oi, S., Babapour, B., Kaito, N., Ohashi, K., Ebara, M., Kato, M., and Abe, T. (2002). Neuroendoscopic placement of Ommaya reservoir into a cystic craniopharyngioma. Childs Nerv. Syst. 18, 629-633.

Julow, J., Backlund, E. O., Lanyi, F., Hajda, M., Balint, K., Nyary, I., and Szeifert, G. T. (2007). Longterm results and late complications after intracavitary yttrium-90 colloid irradiation of recurrent cystic craniopharyngiomas. Neurosurgery 61, 288-295; discussion 295-286.

Kim, S. -D., Park, J. -Y., Park, J., Lee, J. -B., Kim, S. -H., and Lim, D. -J. (2007). Radiological findings following postsurgical intratumoral bleomycin injection for cystic craniopharyngioma. Clin. Neurol. Neurosurg. 109, 236-241.

Kramer, S., McKissock, W., and Concannon, J. P. (1961). Craniopharyngiomas. Treatment by combined surgery and radiation therapy. $J$. Neurosurg. 18, 217-226.

Kubo, O., Takakura, K., Miki, Y., Okino, T., and Kitamura, K. (1974). Intracystic therapy of bleomycin for craniopharyngioma-effect of bleomycin for cultured craniopharyngioma cells and intracystic concentration of bleomycin (author's transl). No Shinkei Geka 2, 683-688.

Lafay-Cousin, L., Bartels, U., Raybaud, C., Kulkarni, A. V., Guger, S., Huang, A., and Bouffet, E. (2007). Neuroradiological findings of bleomycin leakage in cystic craniopharyngioma. Report of three cases. J. Neurosurg. 107, 318-323.

Linnert, M., and Gehl, J. (2009). Bleomycin treatment of brain tumors: an evaluation. Anticancer Drugs 20, 157-164.

Louis, D. N., Ohgaki, H., Wiestler, O. D., and Cavenee, W. K. (2007). WHO classification of tumours of the central nervous system. International Agency for Research on Cancer, Lyon.

Merchant, T. E., Kiehna, E. N., Kun, L. E., Mulhern, R. K., Li, C., Xiong, X., Boop, F. A., and Sanford, R. A. (2006). Phase II trial of conformal radiation therapy for pediatric patients with craniopharyngioma and correlation of surgical factors and radiation dosimetry with change in cognitive function. J. Neurosurg. 104, 94-102.

Mottolese, C., Stan, H., Hermier, M., Berlier, P., Convert, J., Frappaz, D., and Lapras, C. (2001). Intracystic chemotherapy with bleomycin in the treatment of craniopharyngiomas. Childs Nerv. Syst. 17, 724-730.

Mottolese, C., Szathmari, A., Berlier, P., and Hermier, M. (2005). Craniopharyngiomas: our experience in Lyon. Childs Nerv. Syst. 21, 790-798.

Müller, H. L. (2010). Childhood craniopharyngioma-current concepts in diagnosis, therapy and follow-up. Nat. Rev. Endocrinol. 6, 609-618.

Müller, H. L., Albanese, A., Calaminus, G., Hargrave, D., Garre, M. L., Gebhardt, U., Saran, F., Sorensen, N., and Spoudeas, H. A. (2006). Consensus and perspectives on treatment strategies in childhood craniopharyngioma: results of a meeting of the Craniopharyngioma Study Group (SIOP), Genova, 2004. J. Pediatr. Endocrinol. Metab. 19(Suppl. 1), 453-454.
Musolino, A., Munari, C., Blond, S. Betti, O., Lajat, Y., Schaub, C. Askienazy, S., and Chodkiewicz, J. P. (1985). Stereotaxic treatment of expanding cysts in craniopharyngiomas by endocavitary betairradiation (Re-186; Au-198; Y-90). Neurochirurgie 31, 169-178.

Park, D. H., Park, J. Y., Kim, J. H., Chung, Y. G., Lee, H. K., Lee, K. C., and Suh, J. K. (2002). Outcome of postoperative intratumoral bleomycin injection for cystic craniopharyngioma. $J$. Korean Med. Sci. 17, 254-259.

Park, Y. S., Chang, J. H., Park, Y. G., and Kim, D. S. (2011). Recurrence rates after neuroendoscopic fenestration and gamma knife surgery in comparison with subtotal resection and gamma knife surgery for the treatment of cystic craniopharyngiomas. J. Neurosurg. 114, 1360-1368.

Pettorini, B. L., Inzitari, R., Massimi, L., Tamburrini, G., Caldarelli, M., Fanali, C., Cabras, T., Messana, I., Castagnola, M., and Di Rocco, C. (2010). The role of inflammation in the genesis of the cystic component of craniopharyngiomas. Childs Nerv. Syst. 26, 1779-1784.

Pettorini, B. L., Tamburrini, G., Massimi, L., Caldarelli, M., and Di Rocco, C. (2009). Endoscopic transventricular positioning of intracystic catheter for treatment of craniopharyngioma. Technical note. J. Neurosurg. Pediatr. 4, 245-248.

Pollock, B. E., Lunsford, L. D., Kondziolka, D., Levine, G., and Flickinger, J. C. (1995). Phosphorus-32 intracavitary irradiation of cystic craniopharyngiomas: current technique and long-term results. Int. J. Radiat. Oncol. Biol. Phys. 33, 437-446.

Sadeghi, M., Moradi, S., Shahzadi, S. and Pourbeigi, H. (2007). Dosimetry of (32)P radiocolloid for treatment of cystic craniopharyngioma. Appl. Radiat. Isot. 65, 519-523.

Sanford, R. A. (1994). Craniopharyngioma: results of survey of the American Society of Pediatric Neurosurgery. Pediatr. Neurosurg. 21(Suppl. 1), 39-43.

Savas, A., Arasil, E., Batay, F., Selcuki, M., and Kanpolat, Y. (1999). Intracavitary chemotherapy of polycystic craniopharyngioma with bleomycin. Acta Neurochir. (Wien) 141, 547-548; discussion 549.

Savas, A., Erdem, A., Tun, K., and Kanpolat, Y. (2000). Fatal toxic effect of bleomycin on brain tissue after intracystic chemotherapy for a craniopharyngioma: case report. Neurosurgery 46, 213-216; discussion 216-217.

Stefanou, A., and Siderov, J. (2001) Medical errors. Dosage nomenclature of bleomycin needs to be standardised to avoid errors. BMJ 322, 1423-1424.

Steinbok, P., and Hukin, J. (2010). Intracystic treatments for craniopharyngioma. Neurosurgery 28, E13.

Takahashi, H., Nakazawa, S., and Shimura, T. (1985). Evaluation of postoperative intratumoral injection of bleomycin for craniopharyngioma in children. J. Neurosurg. 62, 120-127.

Takahashi, H., Yamaguchi, F., and Teramoto, A. (2005). Long-term outcome and reconsideration of intracystic chemotherapy with bleomycin for craniopharyngioma in children. Childs Nerv. Syst. 21, 701-704.

Voges, J., Sturm, V., Lehrke, R., Treuer, H., Gauss, C., and Berthold, F. (1997). Cystic craniopharyngioma: long-term results after intracavitary irradiation with stereotactically applied colloidal betaemitting radioactive sources. $\mathrm{Neu}$ rosurgery 40, 263-269; discussion 269-270.

Yang, S. H., Kim, I. S., Hong, J. T., Sung, J. H., Son, B. C., and Lee, S. W. (2009). Intratumoral bleomycin injection as a primary therapy for cystic craniopharyngioma. Neuro-oncology 11, 903.

Zanon, N., Cavalheiro, S., and da Silva, M. C. (2008). Does the choice of surgical approach to insert an intratumoral catheter influence the results of intratumoral cystic treatment? Surg. Neurol. 70, 66-69; discussion 69.

Conflict of Interest Statement: The authors declare that the research was conducted in the absence of any commercial or financial relationships that could be construed as a potential conflict of interest.

Received: 19 October 2011; paper pending published: 29 October 2011; accepted: 24 February 2012; published online: 27 March 2012.

Citation: Bartels U, Laperriere N, Bouffet E and Drake J (2012) Intracystic therapies for cystic craniopharyngioma in childhood. Front. Endocrin. 3:39. doi: 10.3389/fendo.2012.00039

This article was submitted to Frontiers in Pituitary Endocrinology, a specialty of Frontiers in Endocrinology.

Copyright (C) 2012 Bartels, Laperriere, Bouffet and Drake. This is an openaccess article distributed under the terms of the Creative Commons Attribution Non Commercial License, which permits non-commercial use, distribution, and reproduction in other forums, provided the original authors and source are credited. 